\title{
Analytical Laboratory Testing, Not Otherwise Specified
}

National Cancer Institute

\section{Source}

National Cancer Institute. Analytical Laboratory Testing, Not Otherwise Specified. NCI

Thesaurus. Code C113076.

Any analytical testing operation not otherwise specified. 